\title{
Distribution of Silica-Coated Silver/Gold Nanostars in Soft- and Hardwood Applying SERS-Based Imaging
}

\author{
C. Geers, ${ }^{\dagger, \|}$ L. Rodríguez-Lorenzo, ${ }^{\dagger, \|}$ M. I. Placencia Peña, ${ }^{\ddagger}$ P. Brodard ${ }^{\S}$ T. Volkmer, ${ }^{\ddagger}$ \\ B. Rothen-Rutishauser, ${ }^{\dagger}$ and A. Petri-Fink ${ }^{*} \dagger, \perp$ \\ ${ }^{\dagger}$ Adolphe Merkle Institute, University of Fribourg, Chemin des Verdiers 4, 1700 Fribourg, Switzerland \\ ${ }^{\ddagger}$ Architecture, Wood and Civil Engineering, Bern University of Applied Sciences, Solothurnstrasse 102, 2500 Biel, Switzerland \\ ${ }^{\S}$ HES-SO Haute école d'ingénierie et d'architecture, Pérolles 80, 1705 Fribourg, Switzerland \\ ${ }^{\perp}$ Chemistry Department, University of Fribourg, Chemin de Musée 9, 1700 Fribourg, Switzerland
}

\begin{abstract}
Nanoparticles (NPs) in aqueous suspension have just begun to be exploited for the preservative treatment of wood. However, at present, there is very little information available on the distribution of NPs in wood after impregnation, due to associated analytical challenges. In this study, we present the detection of model NPs in softwood and hardwood by surface-enhanced Raman spectroscopy (SERS). SERS is a highly sensitive analytical method requiring no fluorescent labeling. The NP distribution after impregnation is evaluated with one representative species of the two wood types. To show the feasibility of the method, we prepared SERS-active $\mathrm{Au} / \mathrm{Ag}$ nanostars coated with silica to act as a

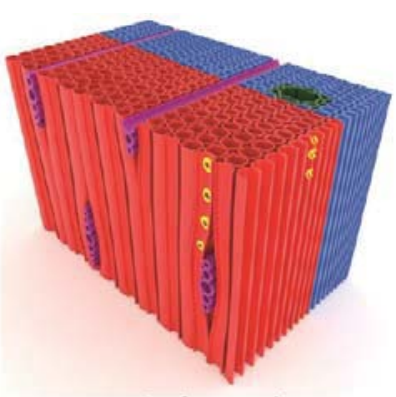

Softwood

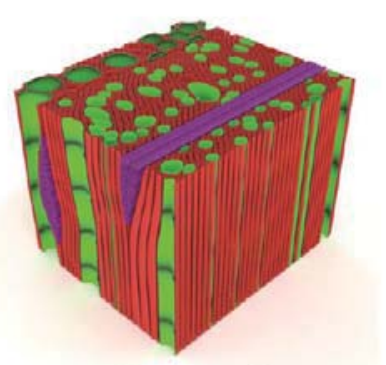

Hardwood model NP system. We show herein that NPs can be imaged in very low quantities in both wood types without any matrix interactions. The presence of the NPs in the wood was confirmed by scanning electron microscopy (SEM) imaging and energy dispersive X-ray analysis (EDX). The fast detection of NPs in a complex matrix, without complicated sample preparation, marks a huge step forward in the development and application of nanotechnology for wood preservation and the quest to optimize the properties of one of the world's most important raw materials.
\end{abstract}

\section{INTRODUCTION}

Wood is one of the oldest materials on the planet, and has found its way into our daily lives since the earliest days of mankind. As a material, wood is exceptionally strong relative to its weight, can be easily fabricated into diverse shapes and sizes, is renewable and biodegradable, and is readily available. However, most wood species are prone to degradation or biodeterioration when exposed to moisture, light, or even organisms such as fungi, cyanobacteria, bacteria, and insects. ${ }^{1}$ Wood preservation is a multibillion-dollar industry ${ }^{1}$ and includes all measures taken to permanently prevent damage or destruction of wood. ${ }^{2}$ Chemical preservatives are most frequently used to treat wood: the major wood preservation product in the United States today is chromated copper arsenate. $^{3}$

In recent years, research on wood preservation has focused on the development of alternative wood preservatives and methods to characterize these preservatives in wood. The most pressing challenge is the reduction or elimination of the use of two common co-biocides, arsenic and chromium, due to their potential environmental issues. ${ }^{4}$ For example, metal oxides such as $\mathrm{TiO}_{2}, \mathrm{ZnO}$, and $\mathrm{CeO}_{2}$ have been used to protect wood surfaces against ultraviolet light and moisture degradation. ${ }^{5,6}$
Calcium and magnesium hydroxides and carbonates, applied using nonaqueous dispersions, were found to be particularly effective preservatives of cellulose-based materials, since they can prevent the degradation catalyzed by acidification processes developing in the wood, which leads to chemical disruption of the cellulose polymer. ${ }^{7}$ Copper, zinc, and boron have played an integral part in the development of wood preservatives responsible for extending the service life of wood products against biodegrading organisms such as fungi and termites. ${ }^{8}$

In recent years, preservatives containing solid copper particles have emerged and begun to compete with aqueous wood preservatives that contain dissolved and/or complexed copper compounds. These so-called "'micronized"' copper particle systems are widely used in today's North American wood preservation market. ${ }^{9}$ The term "'micronized"' implies larger micrometer-sized particles, but all commercially available systems also include much smaller particles $(<100 \mathrm{~nm}$ in diameter). ${ }^{10}$ Apart from micronized copper, general interest in the use of nanoparticles (NPs), alone or in combination with 
existing biocides, as the basis for the next generation of wood protection products is increasing steadily. ${ }^{10-12}$ As a representative example, silver NPs exhibit a broad range of antimicrobial activity. ${ }^{13}$ In the presence of moisture, metallic silver NPs oxidize, which results in the release of silver ions. Because silver oxidation is a slow reaction, the size of the silver NPs is critical to achieve microorganism growth control. ${ }^{14}$

Although an increasing number of researchers are investigating the impregnation process with different NPs, relatively little is currently known about their method of action and their fate. In order to exploit nanotechnology for the development of radically new treatments that could result in large-scale use of nanomaterials in the commercially significant building and construction sector, thorough and comprehensive characterization of promising NPs is needed, as well as an understanding of their distribution into and interaction with the wood structure. ${ }^{11,15}$

In order to analyze NPs in a complex matrix, such as wood, extremely sensitive methods capable of detecting NPs with high resolution are required. Depending on the material and the particle size, some NPs can be detected directly while others require additional labeling. ${ }^{16} \mathrm{NPs}$ can be labeled by different methods; for example, fluorescent labeling combined with microscopic imaging is a very commonly used technique. However, due to the limited resolution of optical microscopy, NPs cannot be imaged individually and only large particles or agglomerates of NPs can be detected. ${ }^{17,18}$ Hence, the autofluorescence of the wood obstructs the characterization of NPs in a wood matrix, and restricts the use of fluorescence spectroscopy when the excitation energy falls in the visible range.

An interesting detection alternative is surface-enhanced Raman spectroscopy (SERS), which is a powerful analytical tool due to its high sensitivity and the fact that it requires no fluorescent labeling. Metal NPs, most prominently Ag, $\mathrm{Au}$, and $\mathrm{Cu}$, are interesting SERS substrates that provide outstanding Raman enhancement factors with respect to the normal Raman signal. ${ }^{19}$ SERS is based on the localized plasmonic enhancement of the Raman signal for molecules adsorbed on a nanostructured surface. The signal enhancement provided by the metallic nanostructures resolves the problem of the intrinsic low cross-section of the Raman process, combining the ultrasensitive potential of this technique with high-throughput chemical information with spatial distributions down to the nanometer scale. Furthermore, the fact that SERS can be carried out under environmental or biological conditions makes it potentially an ideal technique for biochemical imaging. An additional benefit of SERS is that fluorescence is quenched for molecules close to the surface, owing to the additional relaxation pathway available through transfer of energy to the metal surface, which facilitates signal detection.

SERS has been recently deployed by several groups for molecular imaging experiments. During the past few years, the activity in the preparation of SERS encoded NPs to accomplish Raman imaging of different matrices such as cells, tissues, hydrogels, historical arts, and even living subjects has increased notably. ${ }^{20-25}$

$\mathrm{Cu}$ NPs have been also shown to be good SERS substrates with high sensitivity and enhancement factors up to $10^{5} .^{26}$ Since copper is one of the most frequently used biocidal substances in wood preservation and many of the recent formulations contain small $\mathrm{Cu}$ particles, SERS is an excellent analytical tool to analyze impregnation efficiency. In order to demonstrate the feasibility of the method as well as its limitations, we chose a NP model system to analyze NP impregnation in wood. Unfortunately, copper NPs are difficult to reproducibly synthesize, to colloidally stabilize, and are additionally susceptible to oxidation; ${ }^{27}$ thus, we looked to the related coinage metals silver and gold in order to find a suitable NP model system. We present herein the synthesis of SERS-tagged silver/gold nanostars coated with a silica shell encapsulating Nile Blue A (NBA) as potential platforms for SERS imaging. The silica shell was applied to protect the metal core as well as the Raman-reporter and to compare it to published impregnation studies working with spherical model silica $\mathrm{NPs}^{28}$ Silica NPs are inexpensive, can be reproducibly synthesized on large scales, and can be dispersed in high concentrations. Also, silica NPs can be surface-derivatized with organic biocides, thus using the silica particle as a biocide carrier into the deeper wood structure. It shown by Salma et $\mathrm{al}^{29}$ that this approach, using chitin capsules, resulted in reduced biocide leaching. For the reasons stated above, silica NPs have a great potential as wood preservatives. With regard to potential future applications, we pressure impregnated model NPs into wood samples in order to demonstrate that they can be visualized and to evaluate the impregnation of NPs in the wood structure. We chose and analyzed pine (Pinus sylvestris) as a representative softwood and beech (Fagus sylvatica) as hardwood, both of which we analyzed for SERS-encoded NPs after impregnation.

The visualization of NPs in a complex matrix is very challenging. Light microscopy does not provide sufficient resolution for ultrasmall particles, and transmission electron microscopy (TEM) is challenging because of sample preparation, which can impact the nanoparticle deposition. We showed for the first time that SERS, which is widely used in biological imaging, can be applied for detection of NPs in wood. SERS measurements can be accomplished with high sensitivity, facile and fast sample preparation, and low interference with the matrix material. Additionally SERS is applicable for relevant, intrinsically biocidal nanomaterials like $\mathrm{Ag}$ or $\mathrm{Cu}$ in combination with organic co-biocides, for example, tebuconazole.

\section{EXPERIMENTAL SECTION}

Wood. The wood species used were beech (Fagus sylvatica) and pine (Pinus sylvestris), and all samples were selected according to EN113. ${ }^{30}$ The wood samples were cut into pieces of size $30 \times 10 \times 10$ $\mathrm{mm}^{3}$ for impregnation. The cross sections of the wood pieces were covered with solvent-free glue. The control by gravimetric analysis after impregnation was omitted as it is not applicable for low concentrations of NPs impregnated in wood.

Synthesis of Silver/Gold Nanostars (AgAu NSs). Gold nanostars (Au NSs) were prepared by adding poly(vinylpyrrolidone) (PVP; $M_{w}=10000$; Sigma-Aldrich)-coated gold seeds $([\mathrm{Au}]=5 \times$ $\left.10^{-5} \mathrm{M} ; d=15 \mathrm{~nm}\right)$ in ethanol to a mixture of $\mathrm{HAuCl}_{4}(0.5 \mathrm{mM})$ and $\operatorname{PVP}\left(M_{\mathrm{w}}=8000\right.$; Alfa Aesar; $\left.12.5 \mathrm{mM}\right)$ in $N, N$-dimethylformamide (DMF) under rapid stirring at room temperature. The as-prepared $\mathrm{Au}$ NSs dispersion was purified and concentrated by centrifugation $(4500$ $\mathrm{rpm} 60 \mathrm{~min}$ ) three times, and the pellets were redispersed in ethanol. The final gold concentration $(7.5 \mathrm{mM})$ was estimated from the absorbance at $400 \mathrm{~nm}^{31}$

The silver deposition step was achieved by adding $270 \mu \mathrm{L}$ of concentrated $\mathrm{H}_{2} \mathrm{O}_{2}(30 \% \mathrm{v} / \mathrm{v})$ quickly to $82.7 \mathrm{~mL}$ of Au NSs $([\mathrm{Au}]=$ $0.24 \mathrm{mM})$ in water. Subsequently, $35.6 \mu \mathrm{L}$ of a $0.135 \mathrm{M} \mathrm{AgNO}_{3}$ solution $(0.06 \mathrm{mM}), 4.9 \mu \mathrm{L}$ of a $28 \% \mathrm{NH}_{4} \mathrm{OH}$ solution $\left(\left[\mathrm{NH}_{3}\right]=1\right.$ $\mathrm{mM})$ and $622.6 \mu \mathrm{L}$ of a $0.514 \mathrm{M}$ sodium citrate solution $(4 \mathrm{mM})$ were added to trigger the reduction of silver ions on the Au NSs. Spectral 


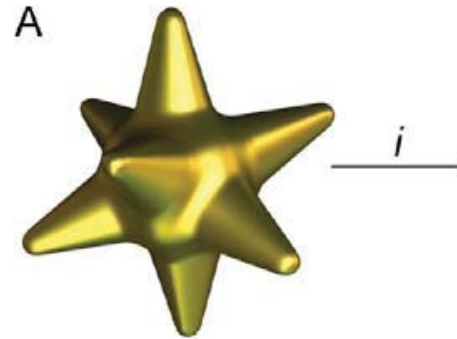

Au nanostar (Au NSs)

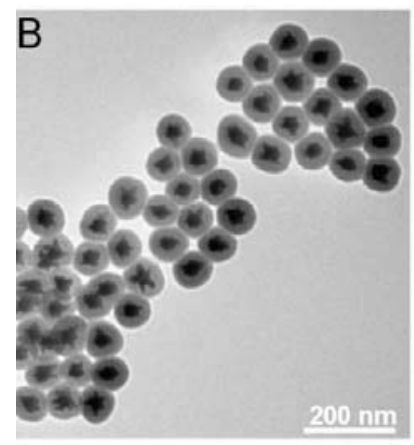

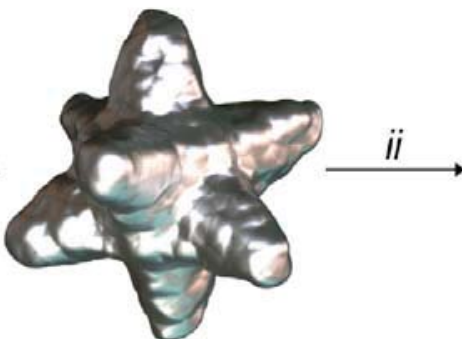

Ag-coated Au nanostar (AgAu NSs)

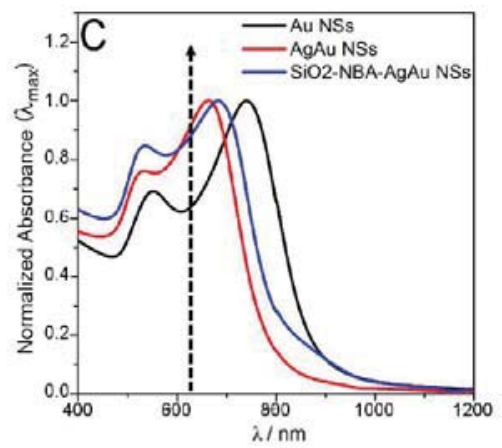

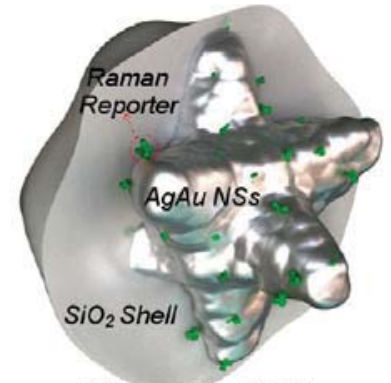

Silica-coated NBAadsorbed $\mathrm{AgAu}$ nanostar (SiO2-NBA-AgAu NSs)

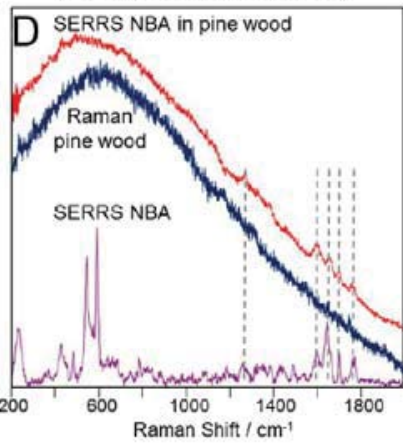

Figure 1. (A) Schematic synthesis of SERRS-encoded NPs: (i) Silver growth on the nanostar surface via $\left[\mathrm{Ag}\left(\mathrm{NH}_{3}\right)_{2}\right]^{+}$reduction with $\mathrm{H}_{2} \mathrm{O}_{2}$. $($ ii $)$ Encoding and silica coating of AgAu NSs through modified Stöber method: Nile Blue A (NBA), which acts as Raman reporter (green dots), is embedded at the core-shell interface. (B) Representative TEM micrograph of $\mathrm{SiO}_{2}$-NBA-AgAu NSs. (C) Vis-NIR spectra of Au NSs as prepared and after silver coating and encoding/silica coating. The arrow indicates the wavelength of the excitation laser (633 nm) for SERRS measurements. (D) The Raman Spectrum of pine wood and SERRS spectra of the encoded NSs on the glass slide and into the wood upon excitation with a $633 \mathrm{~nm}$ laser line.

changes were measured with a Jasco V-670 UV-vis-NIR spectrophotometer after $90 \mathrm{~min}$ of reaction.

Encoding and Silica Coating of $\mathrm{AgAu}$ NSs $\left(\mathrm{SiO}_{2}-\mathrm{NBA}-\mathrm{AgAu}\right.$ NSs). To prepare silica-coated AgAu NSs with an embedded Raman reporter, the $\mathrm{pH}$ of the NP dispersion was adjusted from 9.46 to 6.75 using $1 \mathrm{M} \mathrm{HCl}$. Then, $21.7 \mathrm{mg}$ of PVP aqueous solution was added to the $\mathrm{AgAu}$ NS dispersion. This concentration ratio provided approximately $60 \mathrm{PVP}$ molecules for each square nanometer of particle surface. After $24 \mathrm{~h}$, the NPs were centrifuged (3500 rpm, 40 $\mathrm{min}$ ) and redispersed in $31.7 \mathrm{~mL}$ of ethanol, with a final gold concentration of $0.6 \mathrm{mM}$ (the remaining $\mathrm{H}_{2} \mathrm{O}$ volume was $3.5 \mathrm{~mL}$ ). Then, Nile Blue A (NBA) was added under rapid stirring to a concentration not exceeding $6 \mu \mathrm{M}(210 \mu \mathrm{L}$ of a $1 \mathrm{mM}$ NBA solution $)$ and was allowed to equilibrate for $15 \mathrm{~min}$. Finally, a silica coating was applied following the procedure of Kobayashi et al. ${ }^{32}$ using the following concentrations: $\left[\mathrm{H}_{2} \mathrm{O}\right]=10.55 \mathrm{M}(6.6 \mathrm{~mL})$, [dimethylamine $(\mathrm{DMA})]=0.06 \mathrm{M}(375 \mu \mathrm{L})$, and [tetraethylorthosilicate (TEOS)] $=2$ $\mathrm{mM}(1.4 \mathrm{~mL}$ of $50 \mathrm{~mL}$ TEOS solution). The reaction mixture was allowed to react for $48 \mathrm{~h}$, and the final particles were centrifuged (3000 rpm, $30 \mathrm{~min}$ ) twice and redispersed in $20 \mathrm{~mL}$ of water. Spectral changes were measured with a Jasco V-670 UV-vis-NIR spectrophotometer.

Characterization. Optical characterization was carried out by UV-vis-NIR spectroscopy with a Jasco V-670 spectrophotometer, using $10 \mathrm{~mm}$ path length quartz cuvettes. A Hitachi transmission electron microscope operating at an acceleration voltage of $80 \mathrm{kV}$ was used for particle size analysis (ImageJ).

Impregnation. The dry wood samples were incubated in the NSs suspension in plastic flasks and placed in an autoclave for timber treatment. First a vacuum of -95 mbar was applied for $20 \mathrm{~min}$, followed by a pressure of 5 bar for $1 \mathrm{~h}$. The wood samples were entirely submerged in the NS suspension using a plastic grid. After impregnation, the wood samples were dried at room temperature for at least $48 \mathrm{~h}$.
Surface-Enhanced Raman Scattering. Dried wood samples were carefully split in the radial direction using a scalpel. The exposed wood surface was analyzed upon excitation with a $633 \mathrm{~nm}$ laser line, using a Lab-RAM HR microRaman system from Horiba-Jobin Yvon equipped with a confocal optical microscope, high resolution diffraction grating $(1800 \mathrm{gr} / \mathrm{mm})$, and a Peltier-cooled CCD detector $\left(-70{ }^{\circ} \mathrm{C}\right)$. SERS mapping was carried out in areas of $52 \times 36 \mu \mathrm{m}^{2}$, with a step size of $2.5 \mu \mathrm{m}$, accumulation times of $50 \mathrm{~s}$, and laser power at the sample of $350 \mu \mathrm{W}$. The laser was focused onto the sample by using a $100 \times$ objective (N.A. 0.9) providing a laser spot size of $1 \mu \mathrm{m}$. Data processing was performed with LabSpec 5 (HORIBA Jobin Yvon Inc.). A Multipoint baseline technique was used to adjust those individual spectra, and a polynomial baseline technique was used to adjust the Raman mapping. Raman images were obtained based on the peak intensity of ring stretching at $1643 \mathrm{~cm}^{-1}$ and normalized at maximum intensity of this peak using LabSpec 5 .

Scanning Electron Microscopy (SEM). After SERS analysis, the split wood sample was glued to a graphite plate using conductive carbon paste. The exposed wood surface was coated with a $30 \mathrm{~nm}$ layer of carbon to ensure conductivity. The samples were analyzed on a Mira3 LM (Tescan) FE SEM scanning electron microscope using a secondary electron (SE) detector, and for high resolution images an Inbeam detector. Details regarding the detector, working distance, and voltage can be seen below the respective image.

The samples were mapped using an energy dispersive X-ray spectrometer from EDAX equipped with a lithium-doped silicon detector and analyzed using EDAX Genesis software.

\section{RESULTS AND DISCUSSION}

Preparation of Model Nanoparticles. Figure 1A schematically illustrates the preparation of encoded NPs and the procedure for preparing silica-coated SERS-active silver/ gold colloids. Au NSs were prepared following the method introduced by Kumar et al. ${ }^{33}$ through growth of PVP-coated Au 

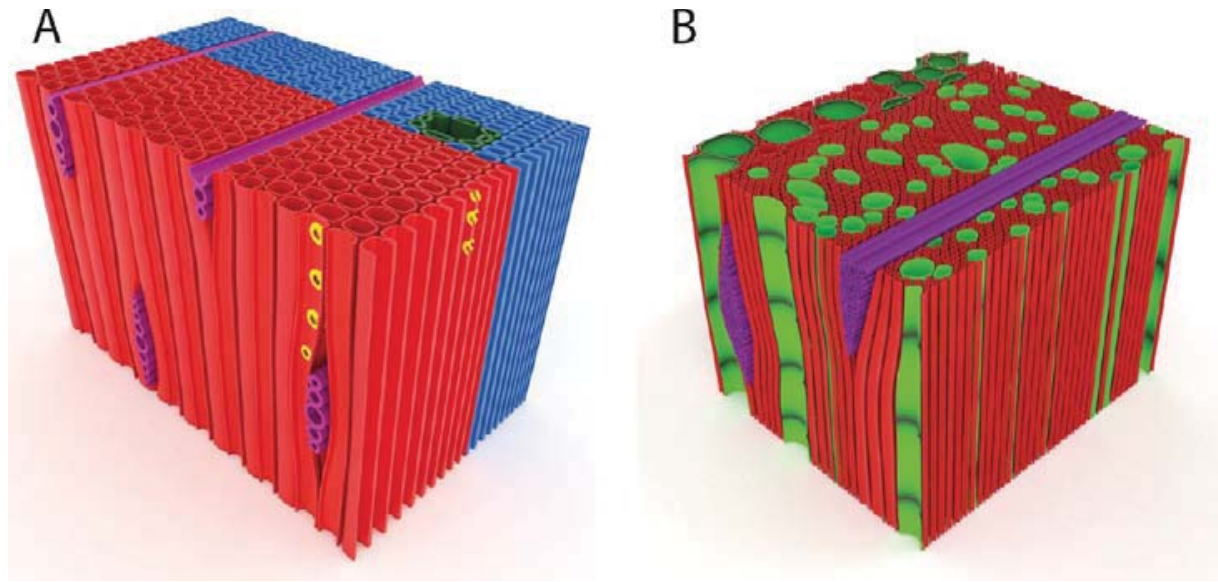

Figure 2. Three-dimensional illustrative images of (A) pine and (B) beech wood. (A) In pine, the distinction between earlywood (red) and latewood (blue) is shown. Dark green depicts a pine resin canal, whereas the bordered pits connecting tracheids in pine wood are indicated in yellow. (B) Large beech vessels are shown in green, with the dark horizontal lines illustrating the separation between the vessel elements. Ray cells, which are present in pine and beech wood, are displayed in purple.

seeds by reduction of $\mathrm{Au}^{3+}$ ions in a concentrated solution of PVP in DMF (Figure 1Ai). Starlike plasmonic NPs were used in this study, since these structures present large local electric field enhancement at the apex of their tips, which has been demonstrated previously by electron energy loss spectroscopy (EELs) mapping and theoretical modeling. ${ }^{34,35}$ Those locally enhanced fields have been exploited to amplify Raman signals (SERS), allowing molecular detection at the zeptomole regime $^{34}$ and have even enabled the detection of single molecule SERS (sm-SERS) on single nanostars. ${ }^{36}$ These Au NSs were subjected to Ag coating by hydrogen peroxide reduction of an aqueous solution of $\left[\mathrm{Ag}\left(\mathrm{NH}_{3}\right)_{2}\right]^{+}$on the gold surface. $^{37,38}$ It is important to note that the NSs preserve their sharp tips after Ag deposition (Figure 1B and Supporting Information Figure S1), which makes them excellent SERSactive substrates as explained above. Moreover, the silver provides an additional enhancement because it is a much more efficient optical material than gold, giving rise to SERS signals 10-100-fold higher than similar Au NPs. ${ }^{39}$ In fact, we have reported previously that the SERRS spectrum of NBA obtained with $\mathrm{SiO}_{2}$-NBA-AgAu NSs was 4-fold higher when compared to that of the "bare" Au NSs coated with silica. ${ }^{28}$ Fales et al. ${ }^{40}$ also reported that the hybrid bimetallic, $\mathrm{Ag} / \mathrm{Au}$, nanostar-based platform exhibits superior resonant SERS properties comparing with single Au NSs.

The preparation of SERS-encoded particles requires adsorption of a Raman-active tag directly on the $\mathrm{Au} / \mathrm{Ag}$ surface. In order to (i) prevent this Raman-reporter tag from leaching, but also to (ii) avoid unspecific adsorption to the NSs surface, (iii) prevent oxidation, and (iv) enhance colloidal stability, the AuAg NSs were subsequently coated with a thin silica layer. Several procedures are available for coating metal NPs with silica. ${ }^{41}$ However, the separation of the required Raman-reporter tag from the surface by the applied silica layer results in the loss of the Raman spectroscopic signatures. Previously reported low SERS intensities for silica-encapsulated $\mathrm{Au}$ NPs are likely to stem from the interference of the silica shell with the reporter. ${ }^{42}$

We have solved this problem by carefully controlling the concentrations of the Raman tag and the PVP prior to silica encapsulation. Therefore, AgAu NSs were protected and transferred into ethanol by addition of PVP. The amount of
PVP added to the nanostars was adjusted to result in $60 \mathrm{PVP}$ molecules per square nanometer of $\mathrm{Au}$ surface, as shown by Graf et al. $^{43}$ This value was chosen as a compromise to maintain colloidal stability during solvent transfer and to allow adsorption of the Raman reporter tag Nile Blue A (NBA) on the $\mathrm{Au}$ surface. In addition, the PVP coating also serves as a primer to facilitate the condensation of silica on the metal surface. ${ }^{43}$ Silica coating was accomplished through a modified Stöber method, involving hydrolysis and condensation of tetraethyl orthosilicate (TEOS) in an ethanol/aqueous solution of DMA (Figure 1Aii). ${ }^{32}$ The resulting SERS encoded particles $\left(\mathrm{SiO}_{2}\right.$-NBA-AgAu NSs) are composed of AgAu NSs with an average diameter of $35 \mathrm{~nm}$ encapsulated in silica with a thickness of approximately $24 \mathrm{~nm}$, resulting in a final particle diameter of $83 \mathrm{~nm}$, measured by TEM (Figure 1B).

Notably, the optical properties of the colloids as prepared, after silver coating, NBA encoding and silica coating (Figure $1 C)$, remained almost unchanged, except for a wavelength shift of the localized surface plasmon resonance (LSPR) band. The growth of a homogeneous $\mathrm{Ag}$ coating on the Au NSs resulted in a blue-shift of $76 \mathrm{~nm}$. This effect can be explained by the hybridization of the dielectric constant of $\mathrm{Au}$ and $\mathrm{Ag}$ in these segregated nanoalloys, according to the plasmon hybridization model. ${ }^{44}$ Notably, the position of the tip plasmon mode is now in a better resonance coupling with the excitation laser line $(633 \mathrm{~nm})$ used for SERS experiments, which provides higher enhancement as has been demonstrated in typical surfaceenhanced Raman excitation spectroscopy (SERES) experiments. ${ }^{45}$ Meanwhile, silica-coated AgAu NSs presented a small red-shift in their tip-plasmon mode, from 664 to $684 \mathrm{~nm}$, which can be ascribed to the increase in local refractive index upon silica coating. ${ }^{46}$ Additionally, this result constitutes evidence that no aggregation has taken place during $\mathrm{Ag}$ and silica coating.

The optical-enhancing activity of encoded particles is shown in Figure 1D, where NBA was excited with a $633 \mathrm{~nm}$ laser line (selected to match perfectly with the NBA absorption band), producing a resonance SERS signal (SERRS). The SERRS signal obtained from the encoded NSs clearly shows the vibrational pattern of NBA, as previously demonstrated ${ }^{28,47}$ ring stretching $\left(1643,1600,1492,1440,1387, \mathrm{~cm}^{-1}\right), \mathrm{CH}$ bending $\left(1258,1185 \mathrm{~cm}^{-1}\right)$, and the in-plane CCC and NCC 

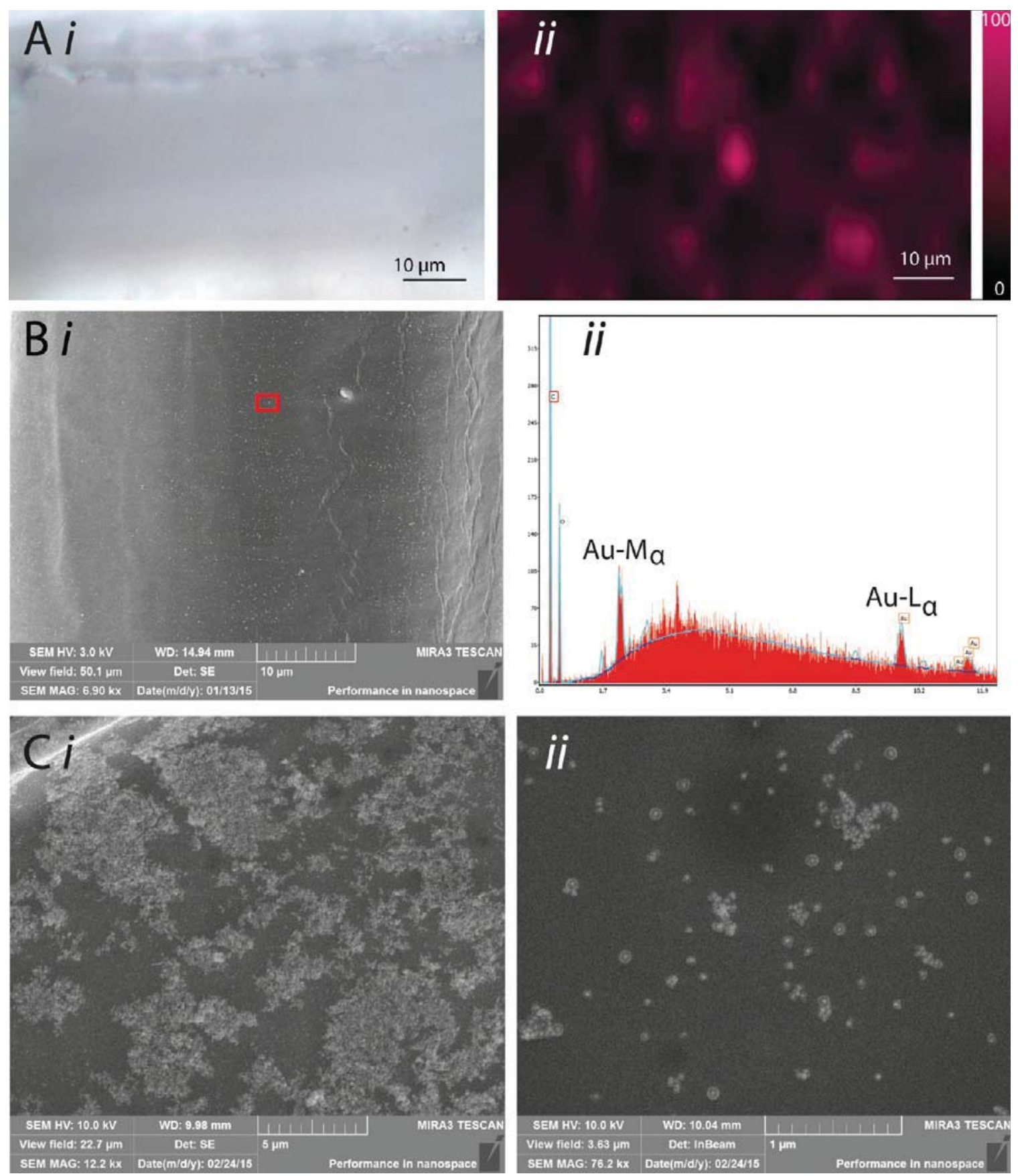

Figure 3. SERRS mapping and SEM images of particle-impregnated beech wood. (A) SERRS mapping of a vessel element of beech wood impregnated with $\mathrm{SiO}_{2}$-NBA-AgAu NSs. (i) White-light optical image of the beech vessel surface. (ii) Corresponding SERRS map (magenta: intensity of ring stretching NBA at $1643 \mathrm{~cm}^{-1}$ ). (B) (i) Scanning electron micrograph of a vessel element of beech wood impregnated with $\mathrm{SiO}_{2^{-}}$ NBA-AgAu NSs. The red rectangle indicates the scan region of the EDX spectrum. (ii) EDX analysis of $\mathrm{SiO}_{2}-\mathrm{NBA}-\mathrm{AgAu}$ NSs on a beech wood vessel element (indicated are the characteristic EDX peaks of $\mathrm{Au}$ ). (C) Scanning electron micrographs of beech wood impregnated with $\mathrm{SiO}_{2}$-NBAAgAu NSs. (i) NSs agglomerates at the connection of two vessel elements. (ii) $\mathrm{SiO}_{2}$-NBA-AgAu NSs on the cell wall of a vessel element. The SERRS maps were acquired upon excitation with a $633 \mathrm{~nm}$ laser line and a spectral window from 1450 to $1700 \mathrm{~cm}^{-1}$ to identify the characteristic peaks of NBA (ring stretching 1643,1600, $1492 \mathrm{~cm}^{-1}$ ).

$\left(598 \mathrm{~cm}^{-1}\right)$, CCC and CNC $\left(554 \mathrm{~cm}^{-1}\right)$, and CCC $\left(499 \mathrm{~cm}^{-1}\right)$ deformations. The well-defined SERRS signal demonstrates the presence of the label within the silica shell, but also that the NBA molecules are close enough to the metal surface to quench the fluorescence. $^{48}$

Consistent with the autofluorescence spectra of the wood, which are generally broad and comprise most of the visible spectra range, ${ }^{49}$ the background spectra of the dry, unloaded (with no NPs) pine wood (blue spectrum in Figure 1D) present a high fluorescence upon excitation using the $633 \mathrm{~nm}$ laser line. As a consequence, the bands at 673 and $595 \mathrm{~cm}^{-1}$, which are significantly enhanced in SERRS and which correspond to the chromophore (phenoxazine), were not observed when the NSs were impregnated in pine wood (red spectrum, Figure 1D) because the detection limit of the method in this spectral window is decreased. ${ }^{48}$ For this reason, 

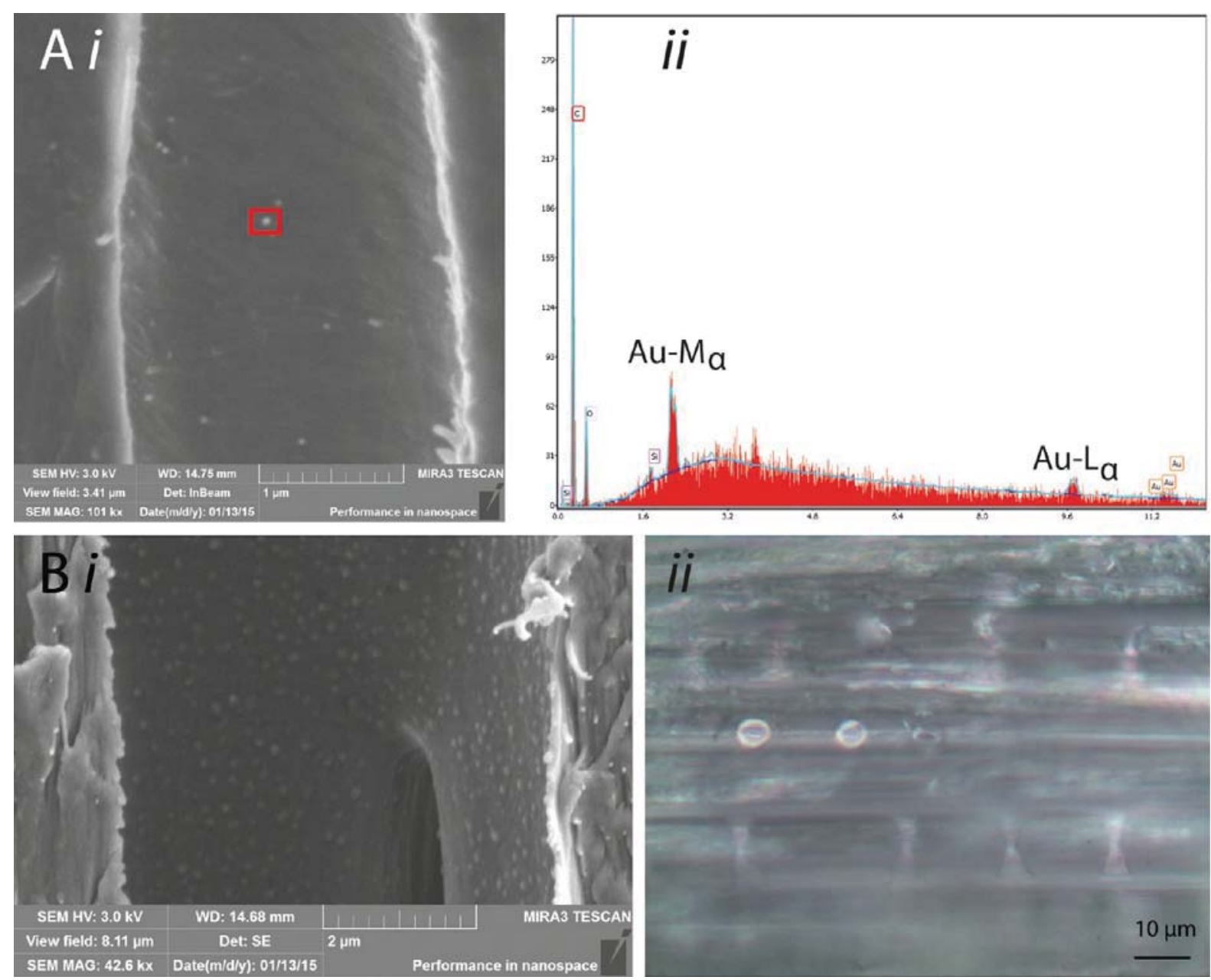

Figure 4. Scanning electron micrographs, EDX measurements, and SERRS mapping of beech wood impregnated with $\mathrm{SiO}_{2}-\mathrm{NBA}-\mathrm{AgAu} \mathrm{NSs}$. (A) Scanning electron micrographs of beech wood impregnated with $\mathrm{SiO}_{2}$-NBA-AgAu NSs. (i) Parenchyma cell. The red rectangle indicates the scan region of the EDX spectrum. (ii) EDX analysis of $\mathrm{SiO}_{2}-\mathrm{NBA}-\mathrm{AgAu} \mathrm{NSs}$ on a beech ray parenchyma cell wall (indicated are the characteristic EDX peaks of Au). (B) (i) Scanning electron micrograph of a fiber cell wall of beech wood impregnated with $\mathrm{SiO}_{2}$-NBA-AgAu NSs. (ii) Overlay of optical image and SERRS map of beech wood fibers. No SERRS signal was visible on the map.

SERRS maps were collected in the same spatial region $(52 \times 36$ $\mu \mathrm{m}^{2}$ ) at the spectral window 1450 to $1700 \mathrm{~cm}^{-1}$ to identify one of the characteristic peaks of NBA (ring stretching $1643 \mathrm{~cm}^{-1}$ ).

Wood Structure and Its Impregnation. To illustrate the complexity of wood, 3D illustrative models depicting the most important wood structures for the impregnation pathways of pine and beech wood were created (Figure 2). The microscopic structures of softwoods such as pine are much simpler, with fewer different cell types. The main cell type in softwoods are long spindle shaped cells called tracheids (90-95\%). Tracheids are arranged in a longitudinal (in the direction of the trunk) direction. Softwoods can be subdivided into earlywood (Figure $2 \mathrm{~A}$ red) and latewood (Figure 2A blue). In some wood genera, this division can be very abrupt, while in others it can be more gradual, with larger cell diameters and thinner cell walls in earlywood, and small diameters with thicker cell walls in the latewood. Softwood tracheids are responsible for both the stability of the wood structure (latewood tracheids) and the conduction of water in the stem (earlywood tracheids). Tracheids are interconnected by bordered pits for fluid transport in the trunk (Figure 2A yellow). Another softwood cell type is ray cells (Figure 2A purple). Rays are ordered in a radial direction (orthogonal to the wood trunk), and are stacked on top of each other. Their main function is the storage of nutrients and they are involved in the water conduction within the tree. Softwood tracheids and ray cells are connected via fenestriform (windowlike) pits. Resin canals (Figure 2A dark green) are not cells, but intercellular spaces surrounded by specialized cells (epithelial cells), that secrete resin to seal damages to the tree and are not involved in water conduction. The structures of hardwoods are much more complex than those of softwoods, and different species can be more variable. The most distinctive feature of hardwoods are the vessels and vessel elements (Figure 2B green), often referred to as pores. In hardwoods, the pores are specialized for the task of transporting water in the trunk. Pores can be connected at their ends by socalled perforation plates, which are holes in the cell membrane. Pores that are parallel to each other can be connected by bordered pits. As in soft woods, ray cells in beech wood are stacked, but they are several cells wide, a phenomenon referred to as multiserate. In hardwoods the difference between earlyand latewood is not always clearly identifiable. Other hardwood cells such as fibers or parenchyma cells are not part of the water conducting system and are therefore not explained further in the scheme of Figure 2B. 

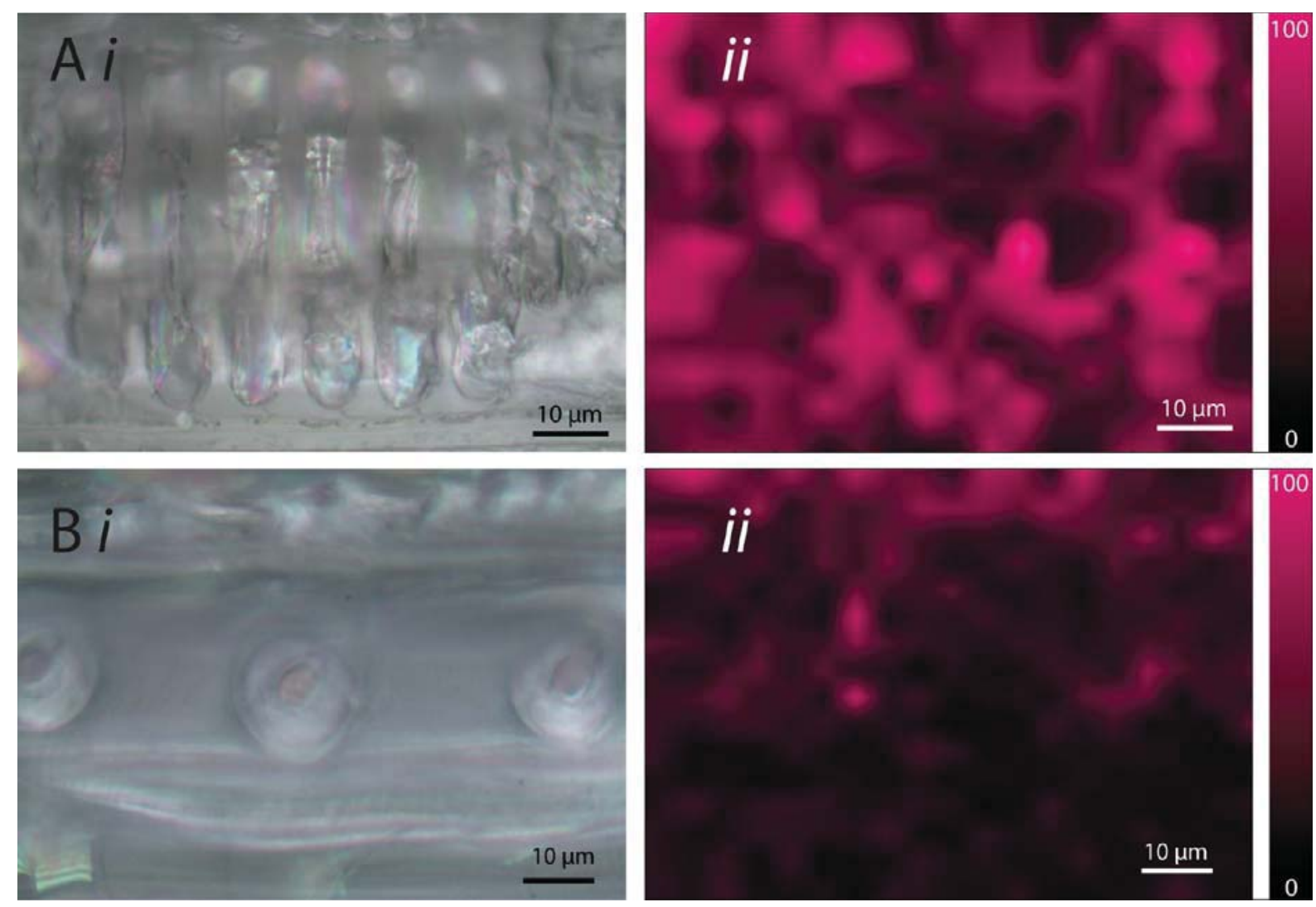

Figure 5. SERRS mapping of pine wood impregnated with $\mathrm{SiO}_{2}-\mathrm{NBA}-\mathrm{AgAu} \mathrm{NSs}$. (A) SERRS mapping of pine wood impregnated with $\mathrm{SiO}{ }_{2}$-NBAAgAu NSs. (i) White-light optical image of fenestriform pits. (ii) Corresponding SERRS map (magenta: intensity of ring stretching NBA at 1643 $\mathrm{cm}^{-1}$ ). (B) SERRS mapping of pine wood impregnated with $\mathrm{SiO}_{2}-\mathrm{NBA}-\mathrm{AgAu}$ NSs. (i) White-light optical image of axial pine wood tracheids with bordered pits. (ii) Corresponding SERRS map (magenta: intensity of ring stretching NBA at $1643 \mathrm{~cm}^{-1}$ ). The SERRS maps were acquired upon excitation with a $633 \mathrm{~nm}$ laser line and a spectral window from 1450 to $1700 \mathrm{~cm}^{-1}$ to identify the characteristic peaks of NBA (ring stretching 1643 , $\left.1600,1492 \mathrm{~cm}^{-1}\right)$.

NSs in Beech Wood. The encoded NSs were pressureimpregnated into wood samples to analyze their localization in the wood structure. Prior to impregnation, the transversal planes of the wood samples were blocked, to prevent impregnation through the opened wood cells. SERRS maps of wood samples that were impregnated with Milli-Q water were analyzed as a control (Figure S2) showing no signal for both wood types.

Figure 3 shows SERRS mapping and SEM images of particleimpregnated beech wood. SEM imaging of $\mathrm{SiO}_{2}-\mathrm{NBA}-\mathrm{AgAu}$ NSs is possible on the large flat vessel cell wall of beech wood. This, however, is an inherent analytical advantage of this particular sample and the roughness of the cell wall of different wood cells or different other structures complicate image analysis.

Figure 3A shows a beech vessel element $(i)$ and the SERRS mapping (ii), revealing the presence of NSs on the vessel cell wall. A secondary electron image of a vessel element cell wall was taken to confirm the presence of NSs (Figure 3Bi). Energydispersive X-ray spectroscopy (EDX) showed the characteristic signal for gold (Figure 3Bii), thereby identifying the white dots as encoded NSs. Vessels are separated in vessel elements connected by large vessel perforations. Large NSs agglomerates were found at the connections of two vessel elements, (Figure $3 \mathrm{Ci}$ ). Since these vessel elements constitute one of the main entries and distribution possibilities for fungi in hardwoods, ${ }^{50}$ it could be advantageous to accumulate biocidal NPs at these positions. As the encoded NPs show high contrast in SEM due to the large difference in molecular weight of the $\mathrm{Ag} / \mathrm{Au}$ core compared to wood (consisting mostly of carbon and oxygen), they can be easily imaged on flat surfaces. ${ }^{51}$ High resolution SEM images reveal the structure of the encoded NSs with bright metallic cores and the less bright silica shells (Figure 3Cii). This demonstrates also the integrity of the encoded particles. Elemental analysis EDX (data not shown) confirmed the presence of $\mathrm{Si}, \mathrm{Ag}$, and $\mathrm{Au}$ in the encoded NSs.

It has been shown previously that preservatives can be found in ray parenchyma cells connected to vessel elements in impregnated hardwood. ${ }^{52}$ Scanning electron micrographs show small amounts of encoded particles on the cell wall of beech ray parenchyma cells, which was also confirmed by EDX (Figure $4 \mathrm{~A})$. Since the encoded NSs were only found in parenchyma cells in the immediate vicinity of vessel elements, no evidence of radial transport of NSs in beech wood can be given.

In wood fibers, no particles were found; however, the rough structure of the fiber wall hampered the distinction between $\mathrm{NSs}$ and the cell wall structure (Figure $4 \mathrm{~B} i$ ). With EDX analysis, the presence of NSs could not be proven (data not shown) and recorded SERRS maps also confirmed the absence of NSs in fibers (Figure 4Bii).

As an initial conclusion we could show that NSs in the sub$100 \mathrm{~nm}$ range can be pressure-impregnated throughout the vessel element network, whereas no penetration of particles into beech wood was found to occur via tracheids and fibers. 

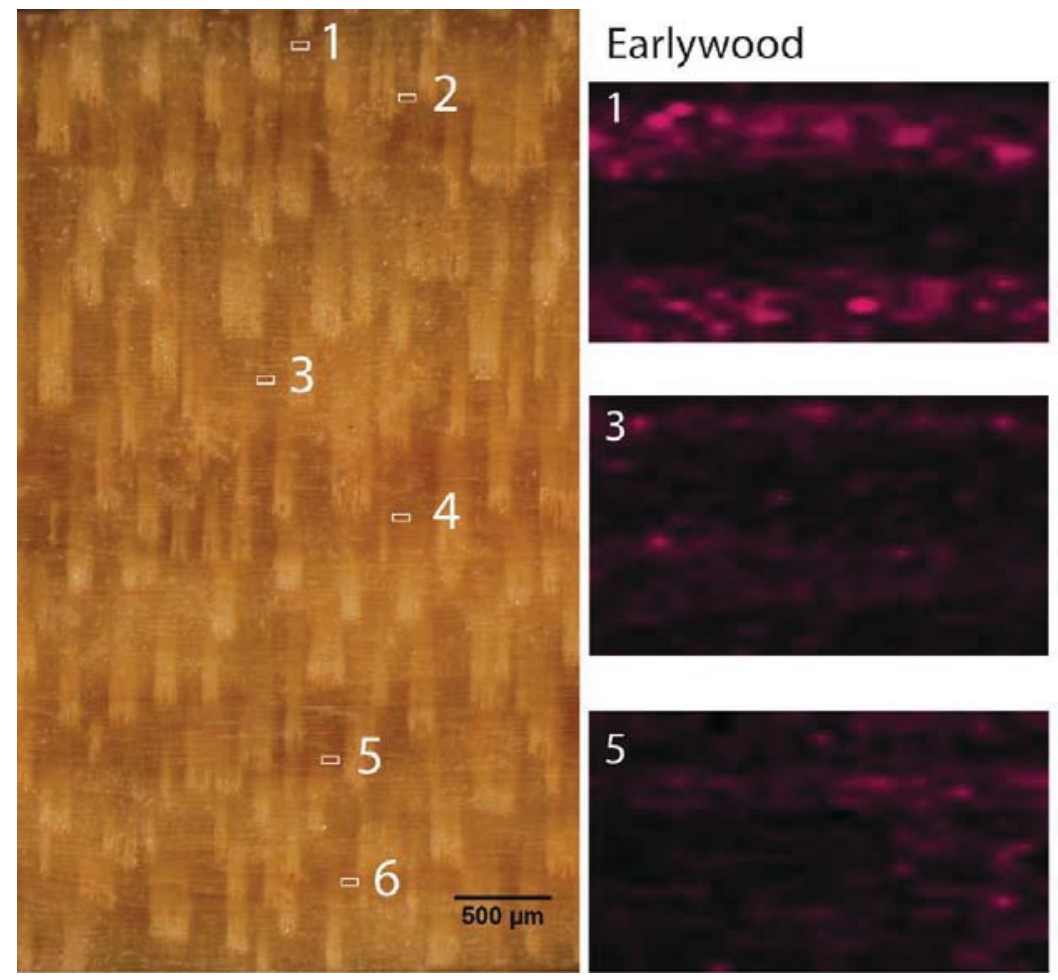

\section{Latewood}
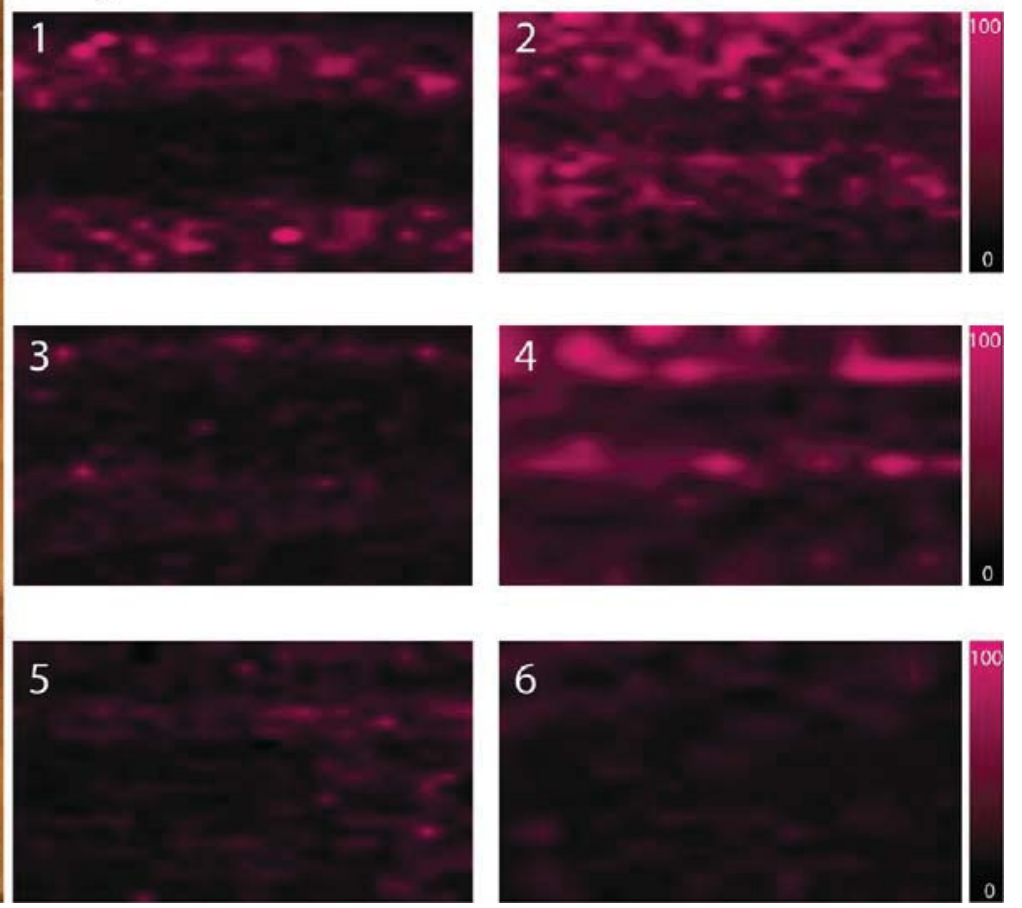

Figure 6. Optical image (white light) of pine wood impregnated with $\mathrm{SiO}_{2}$-NBA-AgAu NSs cut in the radial direction (left). SERRS maps, of earlywood cells $(1,3,5)$ and latewood cells $(2,4,6)$ measured at different impregnation depth. The SERRS maps (baselined intensity at $\left.1643 \mathrm{~cm}^{-1}\right)$ were acquired upon excitation with a $633 \mathrm{~nm}$ laser line.

This is attributed to the size of the particles, which prevents penetration of the pits connecting vessels to fibers and tracheids. Compared to molecular impregnation agents that are well below $10 \mathrm{~nm}$ in size, such as tannins, these results also show that larger particles, such as those used here, are impregnated analogously. ${ }^{53}$

NSs in Pine Wood. The function of water transport in most softwoods is mostly conducted by axial tracheids, which account for $90-95 \%$ of the cells in softwood. ${ }^{54}$ This leads to a more homogeneous impregnation profile than in hardwoods, where water is transported through the much larger pores. Consequently, particles are distributed more evenly throughout the wood in softwoods, resulting in lower local particle concentrations, which still can be easily detected by SERRS because of its high sensitivity. ${ }^{48}$ By SERRS mapping we found $\mathrm{SiO}_{2}$-NBS-AgAu NSs in ray parenchyma cells (Figure 5), which are also known to be part of the water conducting system in softwoods ${ }^{55}$ and therefore allow wood preservatives to enter the wood structure. Ray cells and axial tracheids are connected by fenestriform (windowlike) pits, which enable water transport from the radial to the longitudinal direction. ${ }^{56,57}$ Figure $5 \mathrm{~A}$ shows SERRS maps revealing the presence of NSs on the parenchyma cell wall connected to the rays by the fenestriform pits. Encoded NP deposits were observed in the axial tracheids throughout the entire sample.

In the vicinity of the bordered pits connecting tracheid cells, NP depositions were more concentrated and additional depositions were observed on the pits (Figure 5B), a reliable indication that encoded NSs are passing through the bordered pits that connect the tracheids.

We further analyzed the impregnation depth of encoded NSs in pine wood and the presence of NPs in the latewood cells. Figure 6 shows representative SERRS maps of radial cuts of earlywood and latewood tracheids at different depths of the impregnated wood piece. From the maps, it is apparent that NSs could be detected up to a depth of about $5 \mathrm{~mm}$ in both wood species (Figure 6). The concentration of detected NSs decreased with increasing penetration depth. Earlywood, consisting of thin-walled cells with a larger lumen diameter, is known to be easier to impregnate than latewood, which consists of thick-walled cells with a rather small lumen diameter. ${ }^{54}$ Consequently, the presence of encoded NSs in latewood is very low and in some latewood cells no NSs could be observed at a depth of $5 \mathrm{~mm}$ (data not shown).

Scholz et al. ${ }^{56}$ have shown that waxes are dispersed in axial and longitudinal tracheids after impregnation, due to passing bordered pits and across damaged window-like pits. In analogy, we could demonstrate that sub-100 nm NPs follow the same mechanism of impregnation in pine wood. We also found elevated NP concentrations in the vicinity of bordered pits as shown for micronized copper by Matsunaga et al. ${ }^{11}$ However, micronized copper particles were found to accumulate mostly in the bordered pits, likely due to the bigger size and the more irregular shape of the particles. In another study, Ding et al. ${ }^{58}$ impregnated tebuconazole-loaded chitosan nanocapsules and showed their impregnation in a southern pine sapwood sample. Using slightly smaller particles with a very controlled and narrow size distribution, we could confirm their impregnation in the radial and tangential directions even with wood samples where the cross sections were covered.

\section{CONCLUSION AND OUTLOOK}

In this work, we studied the impregnation profile of NSs in pine and beech wood and showed that the model particles used (around $83 \mathrm{~nm}$ in size) can penetrate both wood types via the cells responsible for water conduction. 
The encoded NPs could be visualized in beech wood by SERRS and high-resolution SEM, and their presence was confirmed by EDX. SERRS mapping helped to visualize low concentrations of the encoded NPs in pine wood.

At present, there is very little information available on the distribution of NPs in wood after impregnation due to the analytical challenges associated with the complicated structure of wood. SERS detection can help image plasmonic NPs (such as copper NPs) in this complex matrix to evaluate their potential and optimize NP-based copper wood preservatives.

\section{ASSOCIATED CONTENT}

\section{S Supporting Information}

The Supporting Information is available

Transmission electron micrographs of Au NSs and AgAu NSs; Raman mapping of control samples of beech and pine wood (PDF)

\section{AUTHOR INFORMATION}

\section{Corresponding Author}

*E-mail: alke.fink@unifr.ch.

\section{Author Contributions}

"C.G. and L.R.-L. contributed equally to this work.

\section{Notes}

The authors declare no competing financial interest.

\section{ACKNOWLEDGMENTS}

This work was financially supported by the Swiss National Foundation (136976), the Adolphe Merkle Foundation and the University of Fribourg. L.R.-L. acknowledges the financial support from the L'Oreal Switzerland and UNESCO's fellowship program "For Women in Science 2013". We would like to thank Dr. Miguel Spuch for preparing the graphics used in this manuscript.

\section{REFERENCES}

(1) Vlosky, R. P. Statistical Overview of the U.S.wood Preserving Industry. Louisiana For. Prod. Dev. Center 2007, 01, 1-81.

(2) Unger, A.; Schniewind, A.; Unger, W. Conservation of Wood Artifacts; Springer-Verlag: Berlin, Heidelberg, 2001; ISBN 9783540415800

(3) The 1996 Wood Preserving Industry Production Statistical Report. Available from American Wood Preservers Institute, 2750 Prosperity Avenue, Suite 550, Fairfax, VA 22031-4312, 2006.

(4) Civardi, C.; Schwarze, F. W. M. R.; Wick, P. Micronized Copper Wood Preservatives: An Efficiency and Potential Health Risk Assessment for Copper-Based Nanoparticles. Environ. Pollut. 2015, 200, 126-132.

(5) Rassam, G.; Abdi, Y.; Abdi, A. Deposition of TiO2 Nano-Particles on Wood Surfaces for UV and Moisture Protection. J. Exp. Nanosci. 2012, 7 (4), 468-476.

(6) Blanchard, V.; Blanchet, P. Color Stability for Wood Products during Use: Effects of Inorganic Nanoparticles. BioResources 2011, 6 (2), 1219-1229.

(7) Baglioni, P.; Giorgi, R. Soft and Hard Nanomaterials for Restoration and Conservation of Cultural Heritage. Soft Matter 2006, 2 (4), 293.

(8) Kartal, S. N.; Green, F.; Clausen, C. A. Do the Unique Properties of Nanometals Affect Leachability or Efficacy against Fungi and Termites? Int. Biodeterior. Biodegrad. 2009, 63 (4), 490-495.

(9) Freeman, M.; McIntyre, C. A Comprehensive Review of CopperBased Wood Preservatives. For. Prod. J. 2008, 58 (11), 6-27.
(10) Evans, P.; Matsunaga, H.; Kiguchi, M. Large-Scale Application of Nanotechnology for Wood Protection. Nat. Nanotechnol. 2008, 3, 577.

(11) Matsunaga, H.; Kiguchi, M.; Evans, P. D. Microdistribution of Copper-Carbonate and Iron Oxide Nanoparticles in Treated Wood. J. Nanopart. Res. 2009, 11 (5), 1087-1098.

(12) Clausen, C. A. Nanotechnology: Implications for the Wood Preservation Industry Nanotechnology: Implications for the Wood Preservation Industry. Int. Res. Group Wood Prot. 2007, 30415.

(13) Franci, G.; Falanga, A.; Galdiero, S.; Palomba, L.; Rai, M.; Morelli, G.; Galdiero, M. Silver Nanoparticles as Potential Antibacterial Agents. Molecules 2015, 20 (5), 8856-8874.

(14) Kourai. The Present State of Development in Inorganic Antibacterial Agents. J. Antibact. Antifung. Agents 1996, 24, 508-515.

(15) Chang, H.; Tu, K.; Wang, X.; Liu, J. Facile Preparation of Stable Superhydrophobic Coatings on Wood Surfaces Using Silica-Polymer Nanocomposites. BioResources 2015, 10 (2), 2585-2596.

(16) Bhirde, A.; Xie, J.; Swierczewska, M.; Chen, X. Nanoparticles for Cell Labeling. Nanoscale 2011, 3 (1), 142-153.

(17) Heintzmann, R.; Jovin, T. M.; Cremer, C. Saturated Patterned Excitation Microscopy-a Concept for Optical Resolution Improvement. J. Opt. Soc. Am. A 2002, 19 (8), 1599-1609.

(18) Hell, S.; Lindek, S.; Stelzer, E. H. K. Measurement of the 4Pi Confocal Axial Resolution Point Spread Function. Appl. Phys. Lett. 1994, 64, 1335-1337.

(19) Muniz-Miranda, M.; Gellini, C.; Giorgetti, E. Surface-Enhanced Raman Scattering from Copper Nanoparticles Obtained by Laser Ablation. J. Phys. Chem. C 2011, 115, 5021-5027.

(20) Zavaleta, C. L.; Smith, B. R.; Walton, I.; Doering, W.; Davis, G.; Shojaei, B.; Natan, M. J.; Gambhir, S. S. Multiplexed Imaging of Surface Enhanced Raman Scattering Nanotags in Living Mice Using Noninvasive Raman Spectroscopy. Proc. Natl. Acad. Sci. U. S. A. 2009, 106 (32), 13511-13516.

(21) Wang, Y.; Seebald, J. L.; Szeto, D. P.; Irudayaraj, J. Biocompatibility and Biodistribution of Surface-Enhanced Raman Scattering Nanoprobes in Zebrafish Embryos: In Vivo and Multiplex Imaging. ACS Nano 2010, 4 (7), 4039-4053.

(22) Qian, X.; Peng, X.-H.; Ansari, D. O.; Yin-Goen, Q.; Chen, G. Z.; Shin, D. M.; Yang, L.; Young, A. N.; Wang, M. D.; Nie, S. In Vivo Tumor Targeting and Spectroscopic Detection with Surface-Enhanced Raman Nanoparticle Tags. Nat. Biotechnol. 2008, 26 (1), 83-90.

(23) Jiang, L.; Qian, J.; Cai, F.; He, S. Raman Reporter-Coated Gold Nanorods and Their Applications in Multimodal Optical Imaging of Cancer Cells. Anal. Bioanal. Chem. 2011, 400, 2793-2800.

(24) Schütz, M.; Steinigeweg, D.; Salehi, M.; Kömpe, K.; Schlücker, S. Hydrophilically Stabilized Gold Nanostars as SERS Labels for Tissue Imaging of the Tumor Suppressor p63 by Immuno-SERS Microscopy. Chem. Commun. 2011, 47 (14), 4216-4218.

(25) Kim, C.; Song, H.-M.; Cai, X.; Yao, J.; Wei, A.; Wang, L. V. In Vivo Photoacoustic Mapping of Lymphatic Systems with PlasmonResonant Nanostars. J. Mater. Chem. 2011, 21 (9), 2841-2844.

(26) Dendisova-Vyskovska, M.; Prokopec, V.; Člupek, M.; Matějka, P. Comparison of SERS Effectiveness of Copper Substrates Prepared by Different Methods: What Are the Values of Enhancement Factors? J. Raman Spectrosc. 2012, 43 (2), 181-186.

(27) Tilaki, R. M.; Iraji zad, A.; Mahdavi, S. M. Size, Composition and Optical Properties of Copper Nanoparticles Prepared by Laser Ablation in Liquids. Appl. Phys. A: Mater. Sci. Process. 2007, 88 (2), 415-419.

(28) Geers, C.; Peña, M. I. P.; Brodard, P.; Volkmer, T. Visualization of Gold/Silver Nanostars in Wood by Surface Enhanced Raman Spectroscopy Spectroscopy. Int. Res. Group Wood Prot. 2014, 30653.

(29) Salma, U.; Chen, N.; Richter, D. L.; Filson, P. B.; DawsonAndoh, B.; Matuana, L.; Heiden, P. Amphiphilic Core/Shell Nanoparticles to Reduce Biocide Leaching From Treated Wood, 1 Leaching and Biological Efficacy. Macromol. Mater. Eng. 2010, 295 (5), 442-450.

(30) British Standards Institute Staff. Wood Preservatives. Test Method for Determining the Protective Effectiveness against Wood Destroying 
Basidiomycetes - Determination of the Toxic Value; British Standards Institution: London, 1996; ISBN 0580273245.

(31) Scarabelli, L.; Grzelczak, M.; Liz-Marzán, L. M. Tuning Gold Nanorod Synthesis Through Pre-Reduction with Salicylic Acid. Chem. Mater. 2013, 25 (21), 4232-4238.

(32) Kobayashi, Y.; Katakami, H.; Mine, E.; Nagao, D.; Konno, M.; Liz-Marzán, L. M. Silica Coating of Silver Nanoparticles Using a Modified Stöber Method. J. Colloid Interface Sci. 2005, 283 (2), 392396.

(33) Kumar, P. S.; Pastoriza-Santos, I.; Rodríguez-González, B.; Javier García de Abajo, F.; Liz-Marzán, L. M. High-Yield Synthesis and Optical Response of Gold Nanostars. Nanotechnology 2008, 19 (1), 015606.

(34) Rodríguez-Lorenzo, L.; Alvarez-Puebla, R. A.; Pastoriza-Santos, I.; Mazzucco, S.; Stéphan, O.; Kociak, M.; Liz-Marzán, L. M.; García de Abajo, F. J. Zeptomol Detection through Controlled Ultrasensitive Surface-Enhanced Raman Scattering. J. Am. Chem. Soc. 2009, 131 (13), 4616-4618.

(35) Nelayah, J.; Kociak, M.; Stéphan, O.; García de Abajo, F. J.; Tencé, M.; Henrard, L.; Taverna, D.; Pastoriza-Santos, I.; Liz-Marzán, L. M.; Colliex, C. Mapping Surface Plasmons on a Single Metallic Nanoparticle. Nat. Phys. 2007, 3 (5), 348-353.

(36) Hrelescu, C.; Sau, T. K.; Rogach, A. L.; Jäckel, F.; Feldmann, J. Single Gold Nanostars Enhance Raman Scattering. Appl. Phys. Lett. 2009, 94 (15), 153113.

(37) Welch, C. M.; Banks, C. E.; Simm, A. O.; Compton, R. G. Silver Nanoparticle Assemblies Supported on Glassy-Carbon Electrodes for the Electro-Analytical Detection of Hydrogen Peroxide. Anal. Bioanal. Chem. 2005, 382 (1), 12-21.

(38) Rodríguez-Lorenzo, L.; de la Rica, R.; Álvarez-Puebla, R. A.; LizMarzán, L. M.; Stevens, M. M. Plasmonic Nanosensors with Inverse Sensitivity by Means of Enzyme-Guided Crystal Growth. Nat. Mater. 2012, 11 (7), 604-607.

(39) García de Abajo, F. J. Colloquium: Light Scattering by Particle and Hole Arrays. Rev. Mod. Phys. 2007, 79 (4), 1267-1290.

(40) Fales, A. M.; Yuan, H.; Vo-Dinh, T. Development of Hybrid Silver-Coated Gold Nanostars for Nonaggregated Surface-Enhanced Raman Scattering. J. Phys. Chem. C 2014, 118 (7), 3708-3715.

(41) Guerrero-Martínez, A.; Pérez-Juste, J.; Liz-Marzán, L. M. Recent Progress on Silica Coating of Nanoparticles and Related Nanomaterials. Adv. Mater. 2010, 22 (11), 1182-1195.

(42) Mulvaney, S. P.; Musick, M. D.; Keating, C. D.; Natan, M. J. Glass-Coated, Analyte-Tagged Nanoparticles: A New Tagging System Based on Detection with Surface-Enhanced Raman Scattering. Langmuir 2003, 19 (11), 4784-4790.

(43) Graf, C.; Vossen, D. L. J.; Imhof, A.; van Blaaderen, A. General Method To Coat Colloidal Particles with Silica. Langmuir 2003, 19 (17), 6693-6700.

(44) Prodan, E.; Nordlander, P.; Halas, N. J. Electronic Structure and Optical Properties of Gold Nanoshells. Nano Lett. 2003, 3 (10), $1411-1415$.

(45) Zhao, J.; Dieringer, J.; Zhang, X.; Schatz, G. C.; Van Duyne, R. P. Wavelength-Scanned Surface-Enhanced Resonance Raman Excitation Spectroscopy. J. Phys. Chem. C 2008, 112 (49), 19302-19310. (46) Rodríguez-Fernández, J.; Pastoriza-Santos, I.; Pérez-Juste, J.; García De Abajo, F. J.; Liz-Marzán, L. M. The Effect of Silica Coating on the Optical Response of Sub-Micrometer Gold Spheres. J. Phys. Chem. C 2007, 111 (36), 13361-13366.

(47) Alvarez-Puebla, R. a; Contreras-Cáceres, R.; Pastoriza-Santos, I.; Pérez-Juste, J.; Liz-Marzán, L. M. Au@pNIPAM Colloids as Molecular Traps for Surface-Enhanced, Spectroscopic, Ultra-Sensitive Analysis. Angew. Chem., Int. Ed. 2009, 48 (1), 138-143.

(48) Aroca, R. The Interaction of Light with Nanoscopic Metal Particles and Molecules on Smooth Reflecting Surfaces. SurfaceEnhanced Vibrational Spectroscopy; John Wiley \& Sons, Ltd: New York, 2006; pp 35-71.

(49) Billinton, N.; Knight, A. W. Seeing the Wood through the Trees: A Review of Techniques for Distinguishing Green Fluorescent
Protein from Endogenous Autofluorescence. Anal. Biochem. 2001, 291 (2), 175-197.

(50) Taghiyari, H. R. Effects of Nanosilver-Impregnation and AlfalfaIntercropping on Fluid Transfer in Downy Black Poplar Wood. Maderas, Cienc. Tecnol. 2014, 16 (1), 49-62.

(51) Clarke, D. R. Review: Image Contrast in the Scanning Electron Microscope. J. Mater. Sci. 1970, 5 (8), 689-708.

(52) Sano, Y.; Okamura, Y.; Utsumi, Y. Visualizing WaterConduction Pathways of Living Trees: Selection of Dyes and Tissue Preparation Methods. Tree Physiol. 2005, 25 (3), 269-275.

(53) Tondi, G.; Thevenon, M. F.; Mies, B.; Standfest, G.; Petutschnigg, A.; Wieland, S. Impregnation of Scots Pine and Beech with Tannin Solutions: Effect of Viscosity and Wood Anatomy in Wood Infiltration. Wood Sci. Technol. 2013, 47, 615-626.

(54) Sjostrom, E. the Structure of Wood. I nWood Chemistry, second ed.; Academic Press: San Diego, 1993; pp 1-20, Chapter 1, ISBN 9780080925899.

(55) Sedighi-Gilani, M.; Griffa, M.; Mannes, D.; Lehmann, E.; Carmeliet, J.; Derome, D. Visualization and Quantification of Liquid Water Transport in Softwood by Means of Neutron Radiography. Int. J. Heat Mass Transfer 2012, 55 (21-22), 6211-6221.

(56) Scholz, G.; Krause, A.; Militz, H. Exploratory Study on the Impregnation of Scots Pine Sapwood (Pinus Sylvestris L.) and European Beech (Fagus Sylvatica L.) with Different Hot Melting Waxes. Wood Sci. Technol. 2010, 44 (3), 379-388.

(57) Scholz, G.; Van den Bulcke, J.; Boone, M.; Zauer, M.; Bäucker, E.; Van Acker, J.; Militz, H. Investigation on Wax-Impregnated Wood. Part 1: Microscopic Observations and 2D X-Ray Imaging of Distinct Wax Types. Holzforschung 2010, 64 (5), 581-585.

(58) Ding, X.; Richter, D. L.; Matuana, L. M.; Heiden, P. A. Efficient One-Pot Synthesis and Loading of Self-Assembled Amphiphilic Chitosan Nanoparticles for Low-Leaching Wood Preservation. Carbohydr. Polym. 2011, 86 (1), 58-64. 